\title{
Quantitative indices of alcohol effects on the rat
}

\author{
G. M. CARTWRIGHT and L.W. BUCKALEW, University of \\ Southern Mississippi, Hattiesburg. Miss. 39401
}

Six behavioral tasks, as influenced by four alcohol doses, were investigated in an attempt to differentiate between dose level effects with quantitative indices. Four treatment groups of four Ss each received six behavioral tasks. Respiration rate and shock avoidance revealed significant differences for five of six possible mean pairs. The remaining tasks, i.e., light-heat a'ersion, activity, water hazard, and plank walking, provided varied delimitation of dose effects.

Experimental investigation of alcohol as an independent variable has been, to a great extent, minimal. A majority of studies has dealt with only one or two doses and their effect on some response specific task. In general, the selection of an ethanol dose has appeared to be arbitrary. As a consequence, little information is available on the reliable and quantifiable behavioral effects of different alcohol dosages.

Arvola, Sammalisto, \& Wallgren (1958) studied several criteria as tests for level of intoxication in rats. The sliding angle on a tilted plane was found to be the most reliable indicator. Five levels of intoxication were distinguished, with dosage ranging from 0 to $7.2 \mathrm{mg}$ of orally administered alcohol per gram of body weight. In a replication of this study, Friedman \& Ingalls (1960) supported these findings, with both studies indicating the percentage change in response to be a linear function of alcohol dosage.

The purpose of the present study was to obtain reliable quantitative response data associated with differing ethanol dosages. Methodological emphasis was placed on the investigation of a range of behavioral responses or functions as each was effected by a range of dose levels.

\section{SUBJECTS}

Six teen male albino rats, 90 days old, were used as Ss. The average ad lib weight of an $\mathrm{S}$ was $180 \mathrm{~g}$.

\section{APPARATUS}

The balance task apparatus consisted of a $2 \frac{1}{2} \mathrm{ft} \times 1$ in. $x$ 1 in. wooden plank, calibrated in inches, and elevated $18 \mathrm{in}$. Activity was recorded by use of a standard revolving drum. A metal tank, measuring $2 \times 2 \times 2 \mathrm{ft}$ with a $6 \times 6 \mathrm{in}$. square platform raised $1 \mathrm{in}$. above the water line at the center of the tank. was used for the water-hazard task. Stimulus for the light aversion task was provided by one $500-\mathrm{W}$ bulb, placed at the end of a 2-ft long and 1-ft high alley. A 5-sec intermittent shock was delivered to an electrified grid with voltage set at $117 \mathrm{~V}$ ac. A $30 \%$ alcohol solution was used for injections.

\section{PROCEDURE}

Four Ss comprised each of four dosage groups. Doses ranging in $.25 \mathrm{cc}$ intervals from $.25 \mathrm{cc}$ to $1.00 \mathrm{cc}$ per $100 \mathrm{~g} \mathrm{of}$ body weight were used. To avoid any tolerance effect, each dosage group received one of six tasks every other day until each group had experienced all tasks.

Following intraperitoneal injection of one of the four doses, Ss were hand gentled for $5 \mathrm{~min}$ prior to testing. Each of six tasks was then administered with the particular task assignment for any group being ordered by use of a table of random numbers. Task 1 consisted of recording respiration rate for a period of $3 \mathrm{~min}$, with the mean value being taken as representative. For Task 2 , Ss were required to walk a wooden plank $2 \mathrm{ft}$ in length, with the distance covered being recorded. General activity, Task 3 , was measured by the number of rpm recorded for $5 \mathrm{~min}$ in the drum. Task 4, light-heat aversion, was recorded as the latency required for $\mathrm{S}$ to exit a 2 -ft long alley in avoidance of a $500-W$ bulb. Task 5 consisted of
Table 1

Alcohol Dose Effect on Six Behavioral Tasks

\begin{tabular}{lrrrrrrr}
\hline $\begin{array}{l}\text { Mean Comparisons } \\
\text { Alcohol Dose }\end{array}$ & \multicolumn{7}{c}{ Task } \\
\cline { 2 - 6 }$(\mathrm{cc} / 100 \mathrm{~g})$ & 1 & 2 & 3 & 4 & 5 & 6 \\
\hline $1.00-.25$ & $*$ & $*$ & n.s. & $*$ & $*$ & $*$ \\
$1.00-.50$ & $*$ & n.s. & n.s. & $*$ & $*$ & $*$ \\
$1.00-.75$ & n.s. & n.s. & n.s. & $*$ & $*$ & $*$ \\
$.75-.25$ & $*$ & n.s. & n.s. & n.s. & $*$ & n.s. \\
$.75-.50$ & $*$ & n.s. & n.s. & n.s. & $*$ & n.s. \\
$.50-.25$ & $*$ & $*$ & n.s. & n.s. & n.s. & n.s. \\
\hline
\end{tabular}

$* p<.05$

shock-avoidance latency, with the response requiring $S$ to mount an insulated platform adjacent to an electrified grid. Task 6 required $S$ to mount a raised platform located in the center of a water-filled tank; latency was recorded for this response.

\section{RESULTS}

Application of Duncan's new multiple range test to each possible pair of treatment means within each of the six tasks is presented in Table 1. Significance of each dose when compared to another within a given task is due to the effects of the alcohol. Both respiration and shock-avoidance latency measures differentiated between five of the six mean combinations. The remaining tasks showed some degree of differentiation, with activity measurement being unselective as to dose effects.

\section{DISCUSSION}

Significant differences between doses on latency to avoid shock were found for all mean comparisons except the two lower doses $(.50-.25 \mathrm{cc})$. Broadhurst \& Wallgren (1964) reported acquisition of a conditioned avoidance response was insensitive to the effects of small to moderate doses of ethanol, thus the lack of significance for the lower two dose means would be expected. Of interest, however, is that the authors also reported that moderate doses had little effect on avoidance acquisition. Respiratory measurements yielded an orderly progression of differentiation, excluding the $1.00-.75 \mathrm{cc}$ dose comparison. These findings agree with Klingman \& Haag (1958) who reported death in dogs given high dosages of alcohol to be due to respiratory failure. Lack of any degree of dose delimitation by the activity measurement may be due to either the general CNS depressant effect of high doses of alcohol, or due to the design of the apparatus.

Support for a nonspecific effect for site of action with alcohol is obtained by inspection of both the plank-walking task and the water-hazard task (see Table 1). Neither of the two measures provided an orderly separation of dose effects, while each task required physical activity. These results indicate the need for a specification of the site of alcohol influence, as well as the effects of the influence. A point, in fact, is obtained by the use of a heat avoidance situation by Moskowitz \& Asato (1966), who attempted to determine the effects of alcohol on learned responses with both positive and negative reinforcers. The stimulus used was a $1000-\mathrm{W}$ infrared light, with the alcohol dose being $1.2 \mathrm{cc}$ of $30 \%$ alcohol solution per $\mathrm{kg}$ of body weight. The authors reported increased latencies for alcohol injected rats from the negative stimulus. As reported by the present study, the degree of differentiation between the effects of such a stimulus is a function of the dose administered.

As indicated in Table 1, physiological responses 
(autonomic) as represented by respiratory rate, shock avoidance, and swimming, reflect differences at most levels of the range of doses tested. The quantitative amount of alcohol injected appears to be rather nonspecific in behavioral functioning at the lower dosages. Inspection of the various mean pairs reflected a negative linear function of behavioral responsiveness as effected by increasing doses, as reported by Cartwright \& Buckalew (in press).

It was concluded that a cumulative dose effect relationship existed across four alcohol dose levels, with statistically critical differentiation occurring between various dosages on both respiration rate and shock avoidance latency.

REFERENCES

ARVOLA, A., SAMMALISTO, L., \& WALLGREN, H. A. A test for level of alcohol intoxication in the rat. Quarterly Journal of Studies on Alcohol, 1958, 19, 563-572.

BROADHURST, P. L., \& WALLGREN, H. A. Ethanol and the acquisition of a conditioned avoidance response in selected strains of rats. Quarterly Journal of Studies on Alcohol, 1964, 25, 476-489.

CARTWRIGHT, G. M., \& BUCKALEW, L. W. The effects of intraperitoneally administered ethanol dosages on an operant response in albino rats. Southern Journal of Educational Research, in press.

FRIEDMAN, S. L., \& INGALLS, J. W. A note on the tilting-plane technique for measuring the performance of rats in relation to the degree of their alcohol intoxication. Quarterly Journal of Studies on Alcohol, 1960, 21, 211-222.

KLINGMAN, G. I., \& HAAG, H. B. Studies on severe alcohol intoxication in dogs: 1 , Blood and urinary changes in lethal intoxication. Quarterly Journal of Studies on Alcohol, 1958, 19, 203-225.

MOSKOWITZ, H., \& ASATO, H. Effect of alcohol upon the latency of responses learned with positive and negative reinforcers. Quarterly Journal of Studies on Alcohol, 1966, 27, 604-611.

\section{(Continued from page 239)}

condition indicated greater variance under periodic feeding $(F=31.00, \mathrm{df}=14, \mathrm{p}<.001)$.

\section{DISCUSSION}

In order to facilitate discussion each phase of the study will be considered separately.

\section{Phase 1.}

This phase was essentially a replication of Shelley's (1965) study as only animals under ad lib feeding were tested. Social facilitation was demonstrated in these animals which did not support Shelley's results.

\section{Phase 2}

A further test of Shelley's hypothesis as well as a test for results of earlier studies using periodic animals was provided in this phase. It will be recalled that this stage enlisted four conditions: periodic, social, periodic isolated, ad lib social, and ad lib isolated. Results from this phase again gave evidence that social facilitation occurs under ad lib as well as periodic feeding conditions.

A possible explanation for Shelley's results may be the manner in which his animals were fed. In his study, the lab blocks were placed on the cage floors. Possibly because of the crowded situation (eight Ss) in the grouped cages, the food became contaminated by the fecal boll and urine, thus becoming unpalatable to the social Ss.

\section{Phase 3}

The results indicate that social facilitation was influenced by a number of variables. The present results did not support Harlow's (1932) and Tolman's (1964, 1965) hypotheses that social facilitation is dependent upon unrestrained and actively competing animals, for both partial- and visual-social Ss gained as much weight as the complete social Ss under certain conditions. Nor does it seem possible to conclude that facilitation of eating is dependent on imitation of the eating response or to secondary reinforcement, as even isolated Ss gained as much as the social Ss in several instances.

Present social condition affected Ss' weight gain, but no trend across conditions was evident. It was apparent that visual social Ss exhibited a definite decrease in weight under periodic conditions. However, there was no such decrease in visual-social Ss under ad lib conditions, nor did any partial-social Ss decrease in weight as sharply. The visual-social situation seemed to have a unique effect on periodically fed
Ss. Prior social condition also affected Ss' present gain. As indicated in Fig. 1, Ss previously isolated ate more under three conditions-complete isolation, visual social and partial social-than Ss previously grouped. The previously grouped Ss seemed to be "inhibited" under conditions other than complete social. It is possible that Ss perceived both the visual and partial social conditions as "isolated" situations. Thus, previously grouped Ss may have been "inhibited" by these conditions while previously isolated Ss were unaffected. This suggests that social facilitation was influenced by a learning variable, possibly secondary reinforcement from other Ss as suggested by James (1960). Furthermore, it will be recalled that an $\mathrm{F}$ test for variance indicated that the data from the periodic Ss had a greater variance than that from the ad lib Ss. This suggested that the Ss under periodic feeding were more sensitive to the varying social conditions. While the present study suggested that a number of variables influence eating, the present results do not suggest that age is necessarily a critical variable as these adult $S$ s remained sensitive to varying feeding-schedule and social-living conditions. Prior studies, with the exception of Bayer's 1929 classical study done with chickens, have generally investigated the effect of social living arrangement on feeding behavior in nonadult Ss.

\section{REFERENCES}

BAYER, E. Beitrage zur Zweikomponententheorie des Hungers. Zeitschrift für Psychologie, 1929, 112, 1-53. Cited by S. Ross and J. G. Ross, Social facilitation of feeding tehavior in dogs. Journal of Genetic Psychology, 1949, 74, 97-108.

HARLOW, H. F. Social facilitation of feeding in the albino rat. Journal of Genetic Psychology, 1932, $41,211-221$.

JAMES, W. T. The development of social facilitation of eating in puppies. Journal of Genetic Psychology, 1960, 96, 123-127.

JAMES, W. T., \& GILBERT, G. F. The effect of social facilitation of food intake of puppies fed separately and together for the first 90 days of life. British Journal of Animal Behaviour, 1955, 3, 131-133.

ROSS, S., \& ROSS, J. G. Social facilitation of feeding behavior in dogs. Journal of Genetic Psychology, 1949, 74, 97-108.

SHELLEY, H. P. Eating behavior: Social facilitation of social inhibition. Psychonomic Science, 1965, 3, 521-522.

TOLMAN, C. W. Social facilitation of feeding behavior in the domestic chick. Animal Behaviour, 1964, 12, 245-251.

TOLMAN, C. W. The effect of sound tapping on feeding behavior of domestic chicks. Animal Behaviour, 1967, 15, 145-148.

TOLMAN, C. W., \& WILSON, G. F. Social feeding in domestic chicks. Animal Behaviour, 1965, 13, 134-142. 